\title{
Ambient Temperature Fracture Strength of Pure Alumina
}

\author{
G. A. Henshall and N. Q. Nguyen \\ Physical Metallurgy, Joining and Coatings Section \\ Chemistry and Materials Science Department
}

UCRL-ID--105842

DE91 007628

\section{Introduction}

The fracture of alumina copper-vapor laser tubes has led to great interest in the mechanical properties of pure alumina $\left(\alpha-\mathrm{Al}_{2} \mathrm{O}_{3}\right)$ in the Copper Laser Program. In particular, knowledge of the fracture strength of the alumina used to make these tubes is required at temperatures ranging from ambient to $1500^{\circ} \mathrm{C}$. Although there are data for the fracture strength of "pure" alumina in the literature [1-4], the grain size, purity, porosity and fabrication techniques for these materials may vary from those relevant to the material used in the Copper Laser Program. For example, hot pressing was used to fabricate all of the material for which data were found in the literature; material used in the Copper Laser Program is cold pressed. Figure 1 shows the fracture strength of nominally pure alumina as a function of temperature taken from several sources. The strong dependence of fracture strength, $\sigma_{\mathrm{f}}$, on grain size and temperature (above $1000^{\circ} \mathrm{C}$ ) are noteworthy.

The purpose of the work reported here was to confirm that the fracture strength data presented in Fig. 1 reasonably well describe the behavior of the alumina used in the Copper Laser Program. The goal was to make this investigation with the minimum of effort and cost. To this end, only ambient temperature tests were planned. Elevated temperature testing would be much more difficult and expensive, requiring: a high temperature bend testing rig (about $\$ 5-10 \mathrm{~K}$ ), a furnace large enough to contain the bend testing rig $(\$ 5-20 \mathrm{~K}$, depending on the maximum temperature desired) and approximately five to ten times the labor cost as ambient temperature tests. If the room temperature data were in agreement with that shown in Fig. 1, then one could assume that the high temperature strength also would be similar to that reported in the literature. 
This conclusion stems from the fact that the material characteristics affecting high temperature strength (e.g. grain size, porosity, purity, surface condition) are the same as those controlling ambient temperature strength. (Even though grain boundary sliding gives rise to some plasticity at high temperatures, the amount of grain boundary sliding and plasticity is largely controlled by grain size and porosity, which also control ambient temperature strength.) If knowledge of the high temperature strength is deemed to be particularly important, however, elevated temperature testing of the alumina used in the Copper Laser Program may be wise. Finally, if there were discrepancies between the ambient temperature strength measured in this investigation and that reported in the literature, then additional testing at elevated temperatures certainly would be warranted.

\section{Experimental Procedures}

Although it is possible to determine the fracture strength of alumina directly by tensile testing, the brittle nature of the material makes this technique difficult and expensive [5]. For this reason, four-point bend testing was selected as the method for evaluating $\sigma_{\mathrm{f}}$. Four-point bend tests were preferred over three-point bending because the former subjects a much larg wrea of the specimen to the maximum tensile stress [6]. The geometry of the four-point bend test is illustrated schematically in Fig. 2.

Bend testing was performed on rectangular samples cut from $99.5 \%$ pure alumina plates (3.0 in. $\times 2.0$ in. $\times 0.1$ in.) of $96.6 \%$ theoretical density provided by Coors. These plates are made from the same powder as the laser tubes and fabricated using identical cold-press and sinter techniques. It is therefore assumed that the properties of the plates are essentially the same as those of the tubes. Testing of the plates, instead of the tubes themselves, circumvents the problems associated with testing curved specimens.

The microstructure of the as-received material was optically examined in the plane of the plate and on sections transverse to the plane of the plate. No significant differences were 
observed among the different sections. The sections were prepared for optical microscopy by polishing for one week with alumina powder and then etching by a 5 -minute immersion in boiling phosphoric acid. Figure 3 shows the microstructure of a transverse section at $200 \mathrm{X}$ magnification. Notice the bimodal distribution of grain sizes and the presence of some residual porosity. Since the fracture properties of brittle materials correlate better with the size of the larger grains [2], the smallest grains were not included in the grain size analysis. Using the ASTM comparative method, the average size of the larger grains was estimated to be approximately $28 \mu \mathrm{m}$. Direct measurement of 25 random grains yields an average grain size of about $22 \mu \mathrm{m}$. For purposes of comparison with Fig. 1, the average grain size is assumed to be $25 \mu \mathrm{m}$.

Following recommendations on sample geometry available in the literature [6-8], the geometry illustrated in Fig. 4 was used for the four-point bend specimens. Five specimens were machined from a single plate. The optimum testing apparatus is one that uses rollers for the support and loading beams, thus minimizing frictional forces [6,7]. Unfortunately, such an apparatus was unavailable (and quite expensive to purchase), so an apparatus employing blunt "knife-edge" support beams was used. Frictional forces were minimized during testing by lubricating the beams and the sample with WD-40 oil. Since "knife-edge" support beams may cause crushing or other problems when large loads are applied [7], a fairly large support span (2.0 in.) was used to reduce the loads. This provided a span-to-thickness ratio of approximately 18.0, which is well within recommended values [6-8]. The width-to-thickness ratio of approximately 3.6 also complies with 'ecommended practice [6-8].

Testing was done using an Instron Model 1125 screw-driven testing frame, and data were taken at a rate of 5 per second using a DEC LSI-11/73 computer data acquisition system with 16bit A/D conversion. Since only the fracture stress was of interest, only the load was measured as a function of time. Prior to testing, the exact dimensions (width and thickness) of each sample were measured using a micrometer. Measurements were taken at three points along the length of the specimen and an average was computed. In addition, the sample was marked so that the 
point of fracture could be positively determined with respect to the bending rig. Following calibration of the load cell, each sample was carefully placed in the bending rig, lubricated and then deformed using a cross-head speed of $0.005 \mathrm{in} . / \mathrm{min}$. The broken samples have been saved for future scanning electron microscopy of the fracture surfaces, if desired.

\section{Experimental Results and Discussion}

The load vs. time results for the five tests are given in Fig. 5. The non-linearity and variability of the loading curves at small loads are probably due to seating of the various parts of the bending apparatus. From marking the orientation of the samples with respect to the testing apparatus prior to testing, it was observed that the fracture always occurred at or near the left loading point. As discussed by Marschall and Rudnik [7], this indicates that there is some asymmetry in the loading or possibly some defect in the loading beam that causes a stress concentration. This point will be discussed further below.

Table 1 summarizes the fracture stress results, which were obtained using the relationship [7]:

$$
\sigma_{\mathrm{f}}=\frac{3 P a}{b d^{2}}
$$

where $P$ is the maximum load, $b$ and $d$ are the width and thickness of the specimen, and $a$ is defined in Fig. 2. The average fracture stress computed from Tabie 1 is $38.7 \mathrm{ksi}(267 \mathrm{MPa}$ ), with a standard deviation of $\pm 3.84 \mathrm{ksi}( \pm 26.5 \mathrm{MPa})$. The data of Spriggs et al. given in Fig. 1a show that for the average grain size of $25 \mu \mathrm{m}$ the ambient temperature fracture stress should be approximately $40 \mathrm{ksi}$, with a variability of about $\pm 3 \mathrm{ksi}$. Both the average value and the standard deviation obtained in the current study are consistent with the results of Spriggs et al. Therefore, it can be concluded that, despite the fracture location problem described above, the fracture stresses determined in the present study are reasonably accurate. To further verify this conclusion would require additional testing with a more sophisticated and expensive bend test 
apparatus. In any case, the fracture stress measured in this investigation can be considered as a conservative value, since any loading asymmetry would terd to decrease the observed fracture stress.

Based on the finding that the ambient temperature fracture stress for the alumina used in the Copper Laser Program is consistent with that reported in the literature for nominally pure alumina fabricated by other means, it is likely that the elevated temperature fracture strengths are also similar to reported values. This conclusion holds so long as microstructures (e.g. grain size, porosity) remain similar for the different investigations. If, however, long exposure times at elevated temperature increase the grain size of alumina used in the copper lasers beyond that presumably experienced in gathering the data shown in Fig. 1, the strength would be degraded relative to that estimated from Fig. 1. This suggests that it would be useful to perform an annealing study to determine the effects of long-time anneals on the microstructure, possibly in conjunction with additional ambient temperature fracture tests on the exposed material.

\section{Summary and Conclusions}

In order to verify the validity of pure alumina fracture strength data reported in the literature for use in characterizing the material used in the Copper Laser Program, ambient temperature four-point bends tests have been performed. These tests were performed using available material and equipment to ininimize cost and time. For simplicity in testing, 0.1 -in. thick plates of the $99.5 \%$ pure $\alpha$-alumina used in the Copper Laser Program were employed in testing. The conclusions gained from these tests are as follows.

1. There is a bimodal distribution of (equiaxed) grain sizes in the as-received material. The average size of the larger set of grains (believed to te most relevant to fracture strength) is approximately $25 \mu \mathrm{m}$. 
2. Based on the results of five four-point bend tests, the ambient temperature fracture strength of pure alumina used in the Copper Laser Program was determined to be $38.7 \mathrm{ksi}$ (267 MPa) with a standard deviation of $\pm 3.84 \mathrm{ksi}(26.5 \mathrm{MPa})$.

3. These results are comparable with those available in the literature, despite the fact that failure always occurred under the left loading beam. This implies that the results reported here are reasonably accurate, but may be viewed as conservative.

4. Based on the consistency between the results of this investigation and those reported in the literature, it is reasonable to assume that the elevated temperature fracture strength of the $\mathrm{Al}_{2} \mathrm{O}_{3}$ used in the Copper Laser Program will be similar to that reported by others for pure alumina. This conclusion holds so long as elevated temperature exposure affects the microstructure of the alumina used in the Copper Laser Program in the same was as that presumably experienced by others reporting high temperature strength data.

\section{Acknowledgements}

The authors would like to thank Bob Kershaw for performing the metallography and Carol Anderson for assistance with the literature review and for valuable discussions. The technical guidance and support of Nancy Schwertz is gratefully acknowledged.

\section{References}

1. R. M. Spriggs, J. B. Mitchell and T. Vasilos, J. Amer. Ceram. Soc. 47, 323-327 (1964).

2. R. W. Davidge and G. Tappin, Proc. Brit. Ceram. Soc., 15, 47-60 (1970).

3. Y. W. Mai, J. Mater. Sci., 11, 1430-1438 (1976).

4. E. Dörre and H. Hübner, Alumina, Springer-Verlag, Berlin (1984).

5. M. S. Loveday and R. Morrell, in Mechanical Testing of Engineering Ceramics at High

Temperatures, B. F. Dyson, R. D. Lohr and R. Morrell, Eds., Elsevier Applied Science, London (1989). 
6. R. C. Newnham, Proc. Brit. Ceram. Soc., 25, 281-29? (1975).

7. C W. Marschall and A. Rucinick, in Fracture Mechanics of Ceramics, Vol 1, R. C. Bradt, D.

P.H. Hasselman and F. F. Lange, Eds., Plemum Press, New York-London, p.69 - 92 (1973).

8. Annual Book of ASTM Standards, Vol 4.06, C203 - 85. 
Table 1. Fracture Stress Test Results.

\begin{tabular}{ccc} 
Sample Number & Fracture Stress (ksi) & Fracture Stress (MPa) \\
\cline { 1 - 2 } AR1 & 36.2 & 250 \\
AR2 & 37.2 & 256 \\
AR3 & 45.3 & 312 \\
AR4 & 38.5 & 265 \\
AR5 & 36.1 & 249
\end{tabular}


(a)

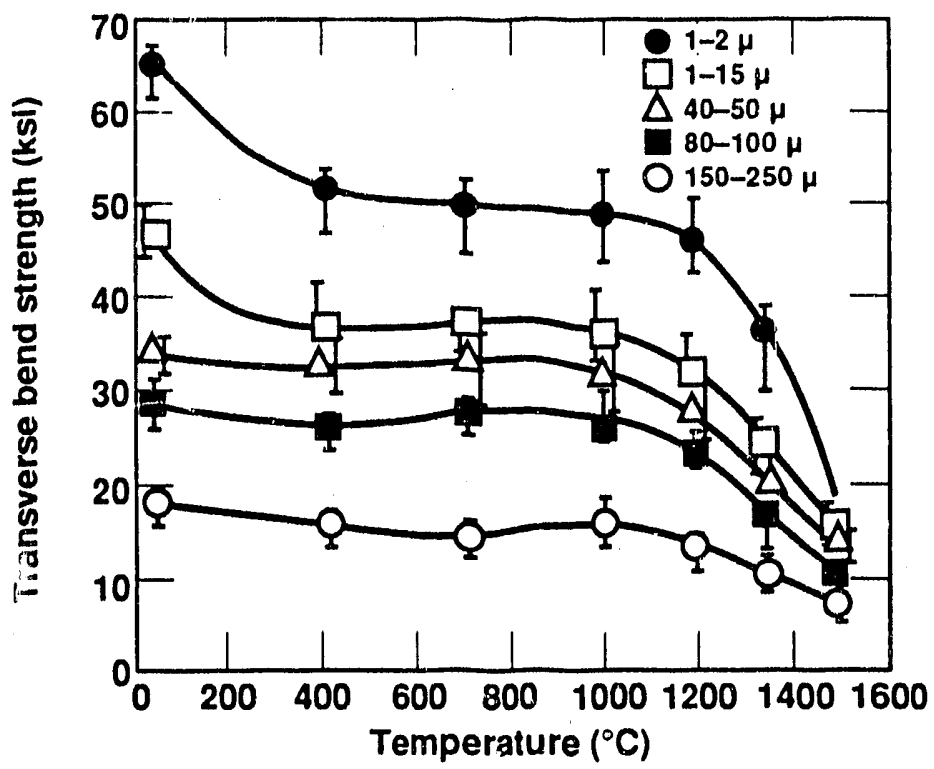

(b)

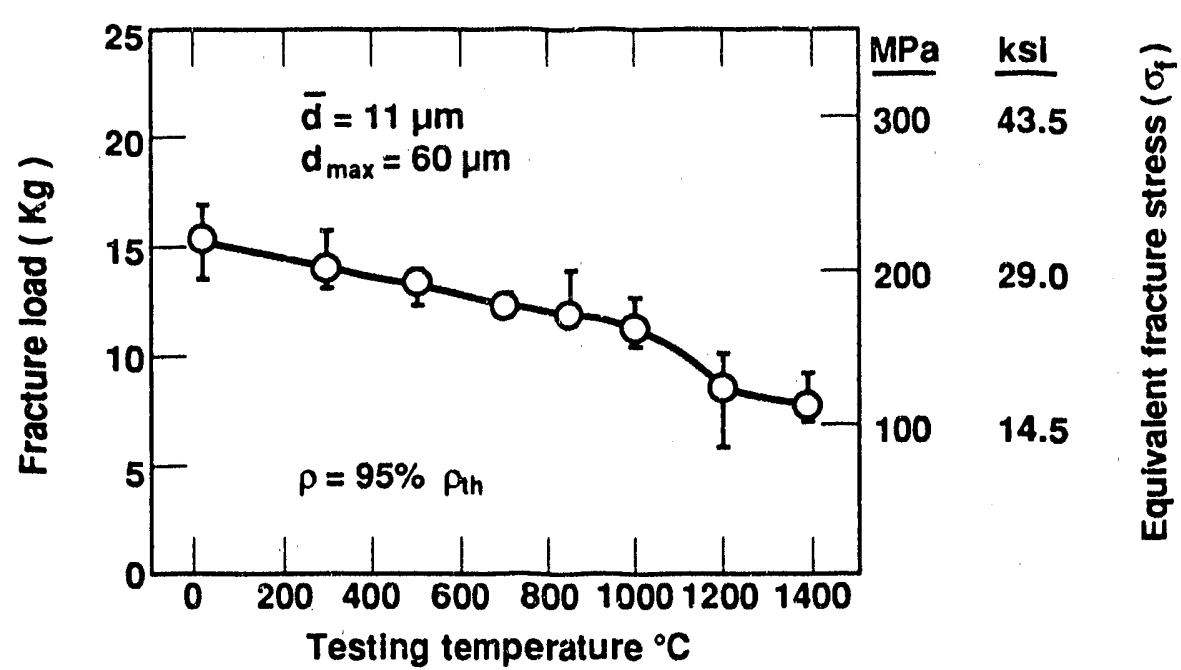

(c)

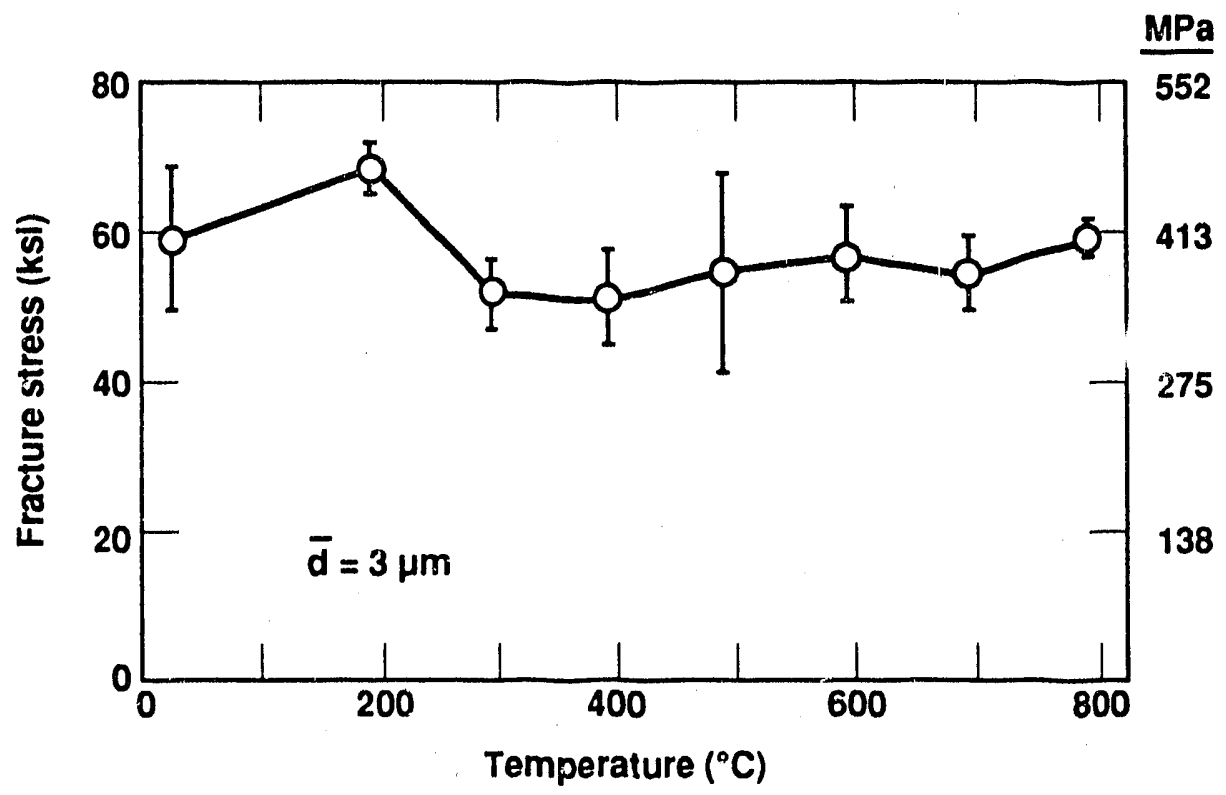

Figure 1. Fracture strength of nominally pure alumina as a function of temperature. Data of: a) Spriggs et al. [1], b) Davidge and Tappin [2] and c) Mai [3]. 


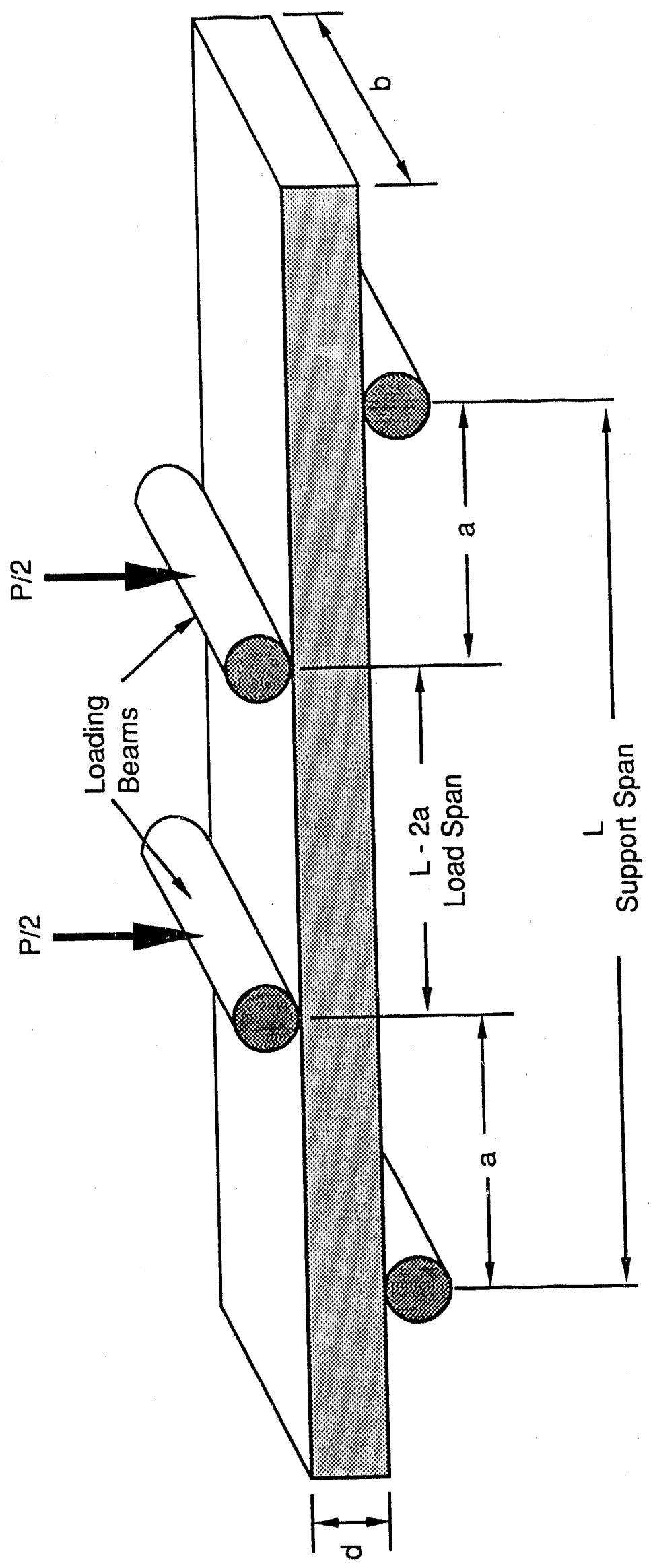

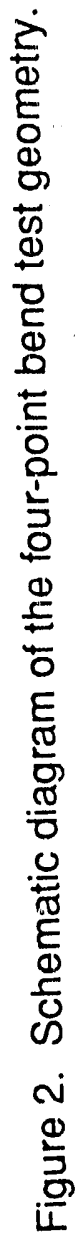




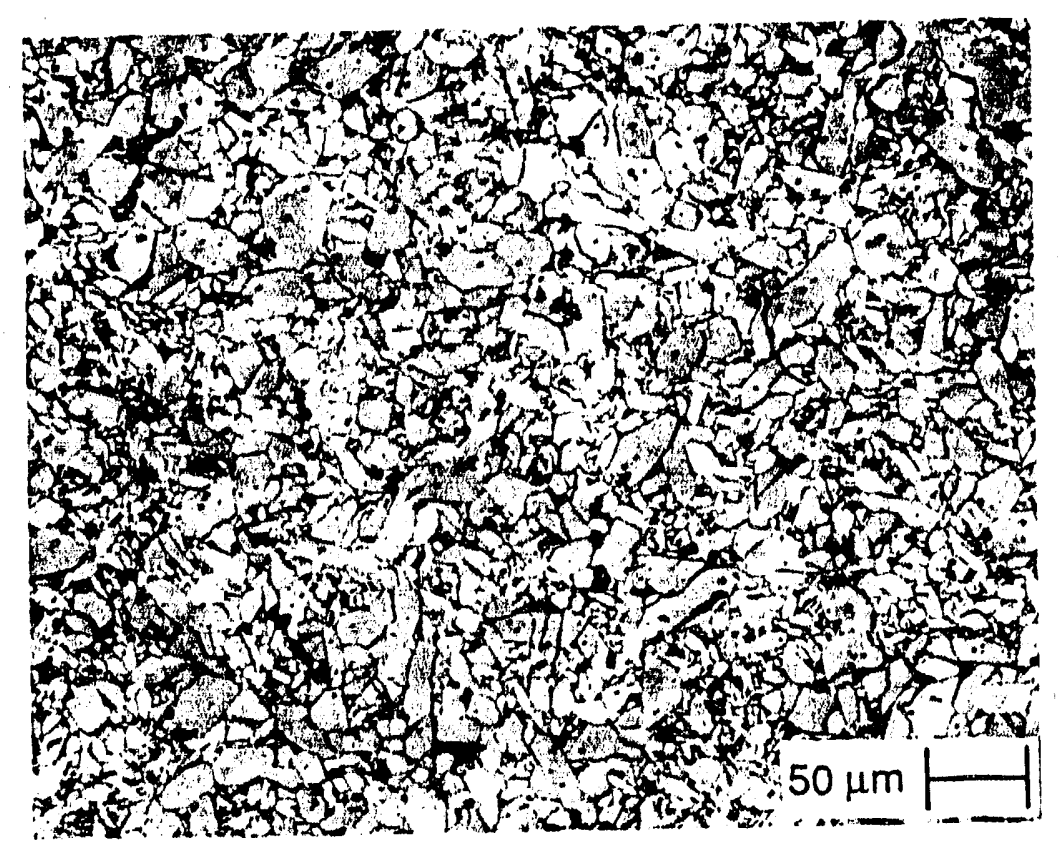

Figure 3. Photomicrograph of a transverse section of the as-received alumina plate. 


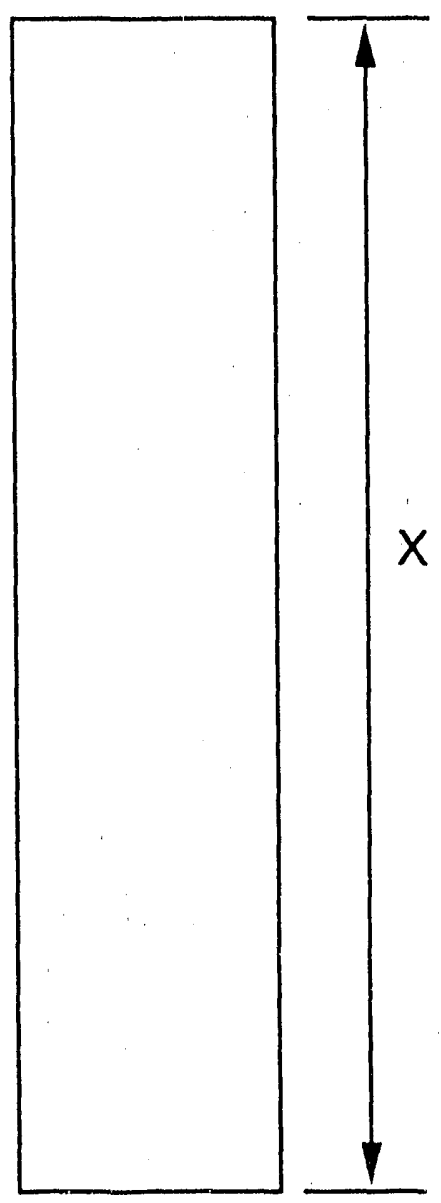

$\mathrm{X}$ : approx. $2.9 \mathrm{in}$.

$Y$ : approx. 0.11 in.

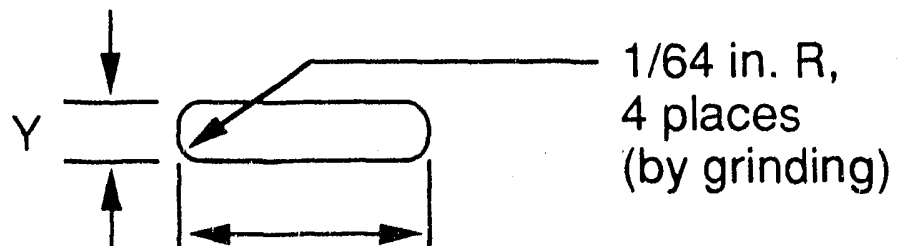

$0.40 \pm .005$

Figure 4. Specimen geometry for the four-point bend tests. 


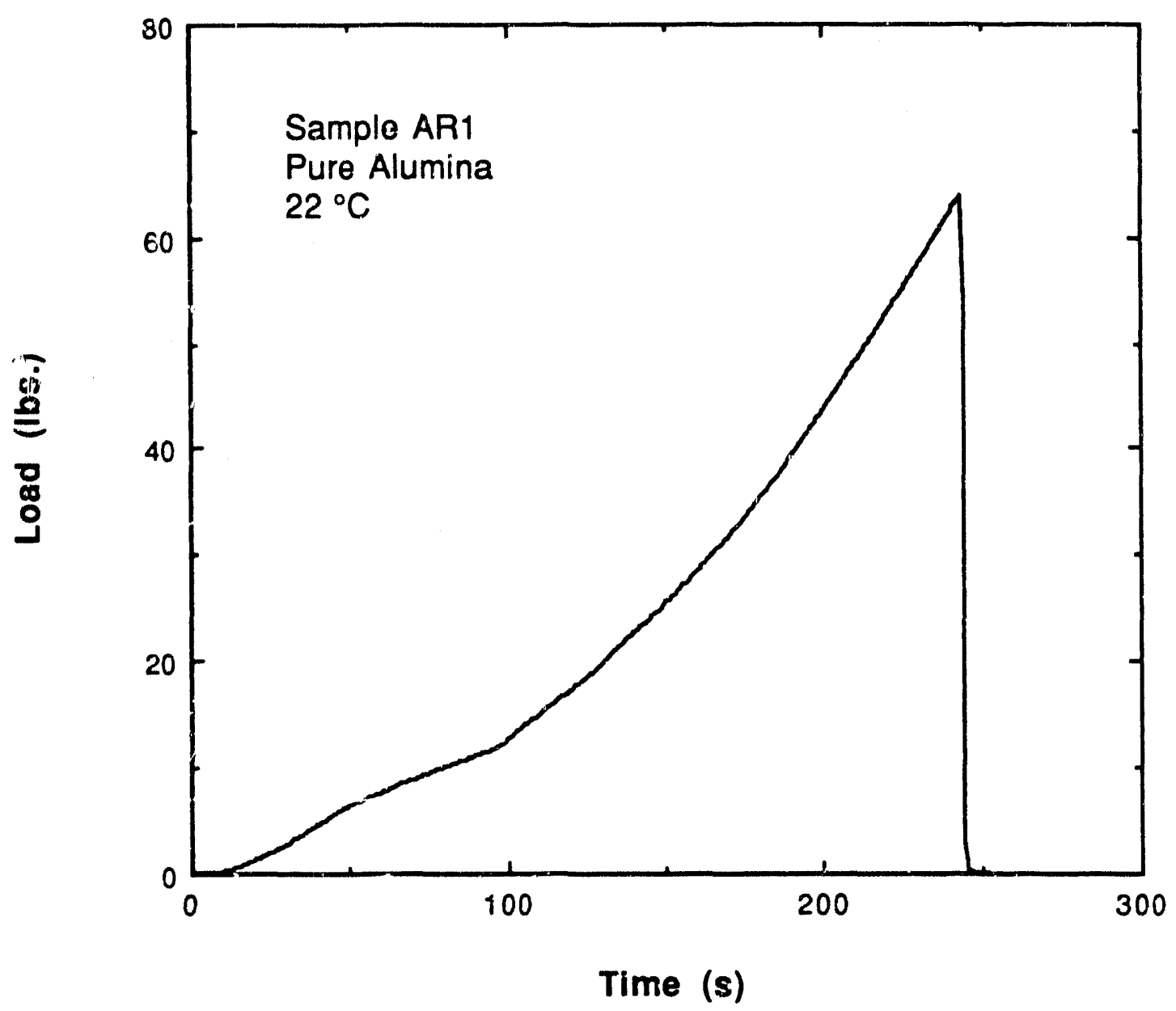

Figure 5a. Load vs time for sample AR1 deformed in four-point bending at a crosshead speed of $0.005 \mathrm{in} . / \mathrm{min}$. 


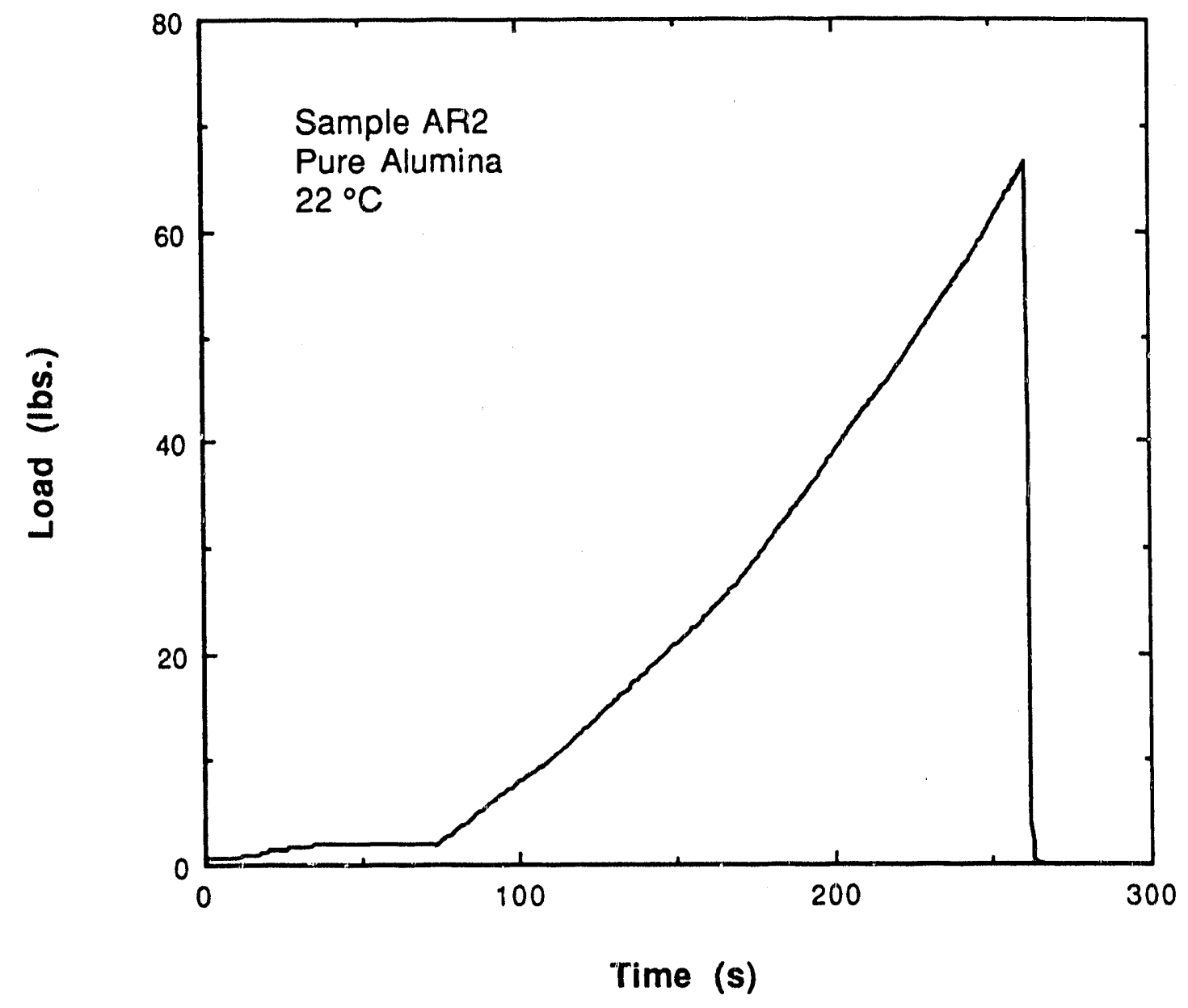

Figure 5b. Load vs time for sample AR2 deformed in four-point bending at a crosshead speed of $0.005 \mathrm{in} . / \mathrm{min}$. 


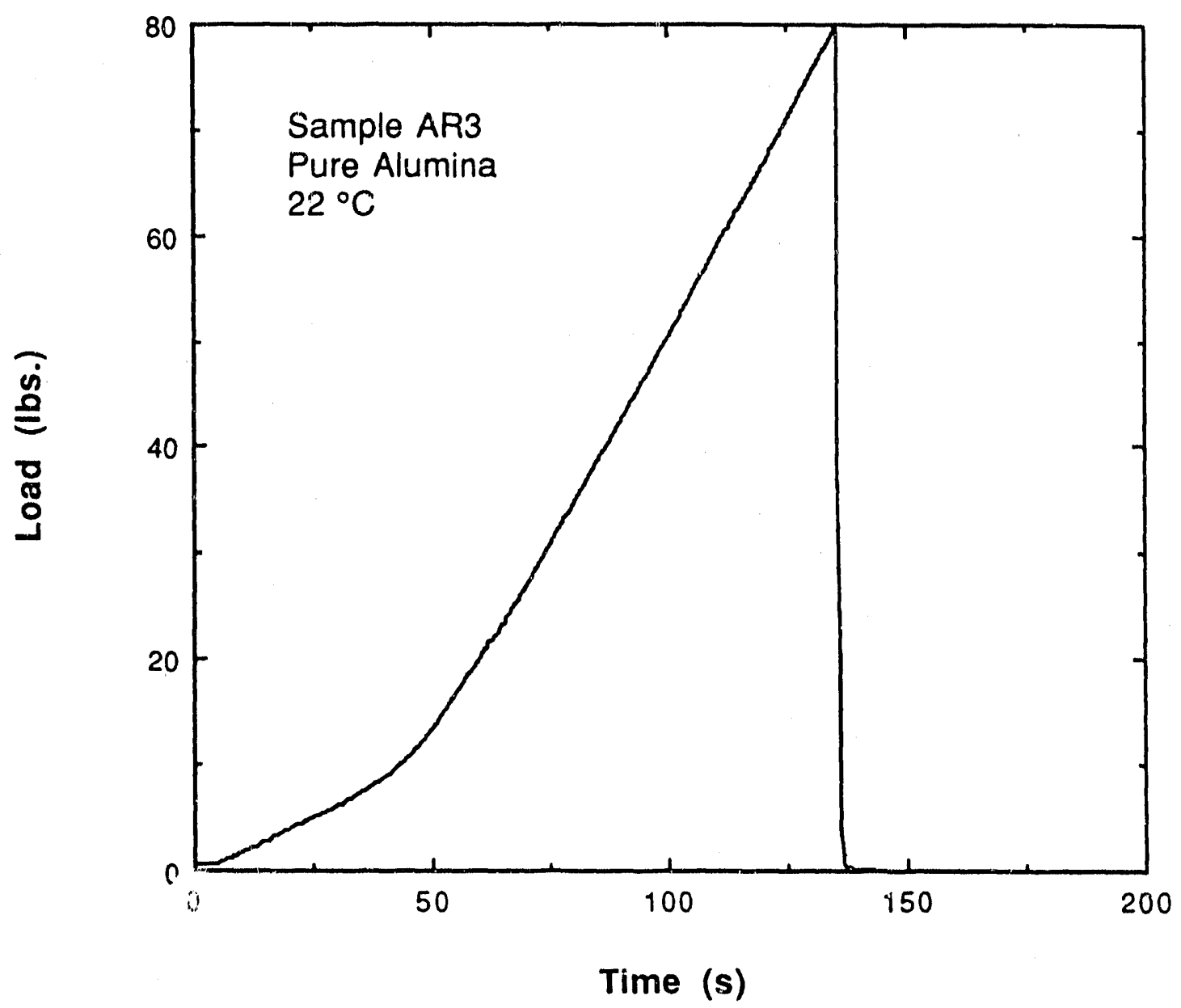

Figure 5c. Load vs time for sample AR3 deformed in four-point bending at a crosshead speed of $0.005 \mathrm{in} . / \mathrm{min}$. 


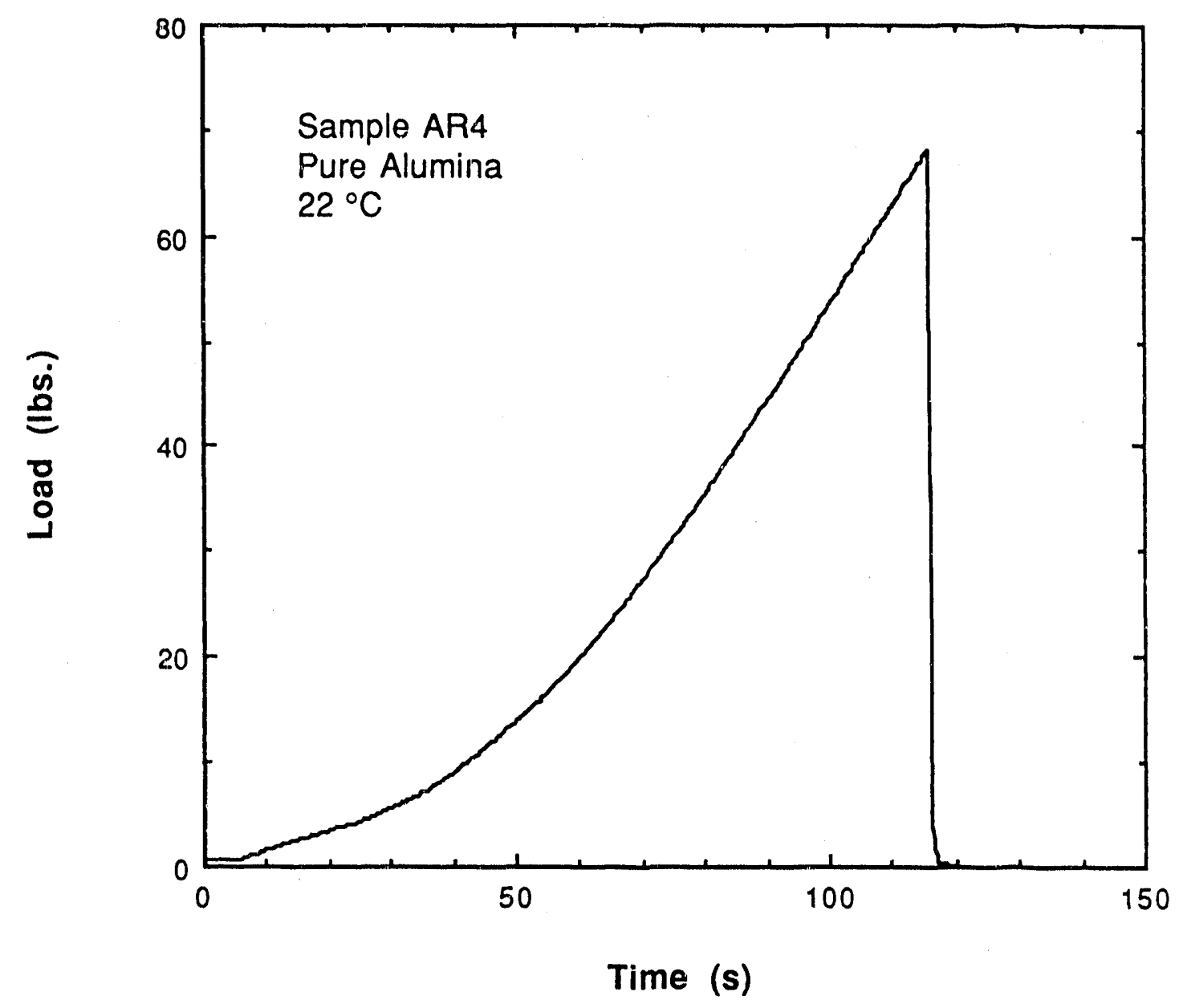

Figure 5d. Load vs time for sample AR4 deformed in four-point bending at a crosshead speed of $0.005 \mathrm{in} . / \mathrm{min}$. 


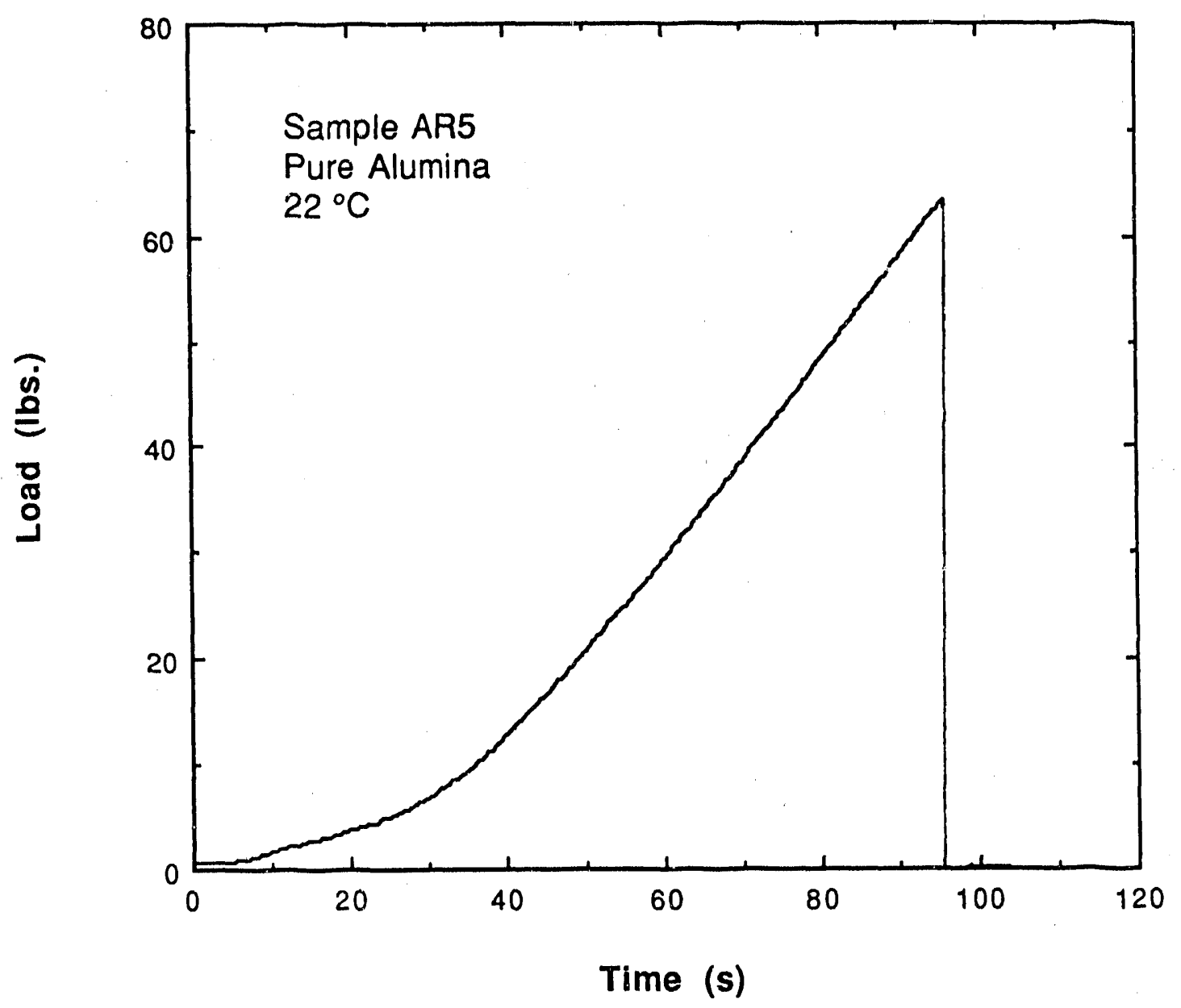

Figure 5e. Load vs time for sample AR5 deformed in four-point bending at a crosshead speed of $0.005 \mathrm{in} . / \mathrm{min}$. 

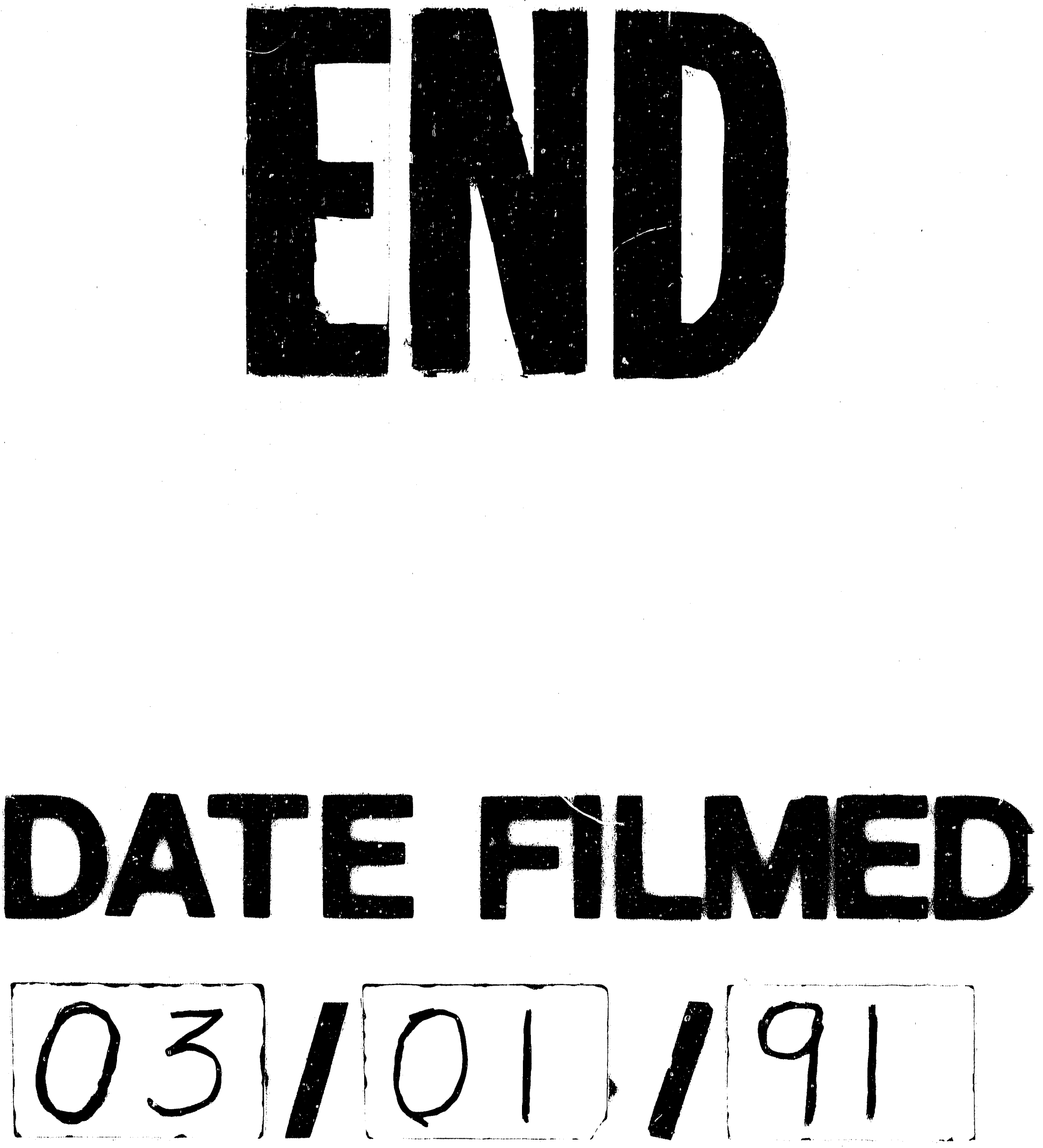
